\title{
First report of Scaevola taccada leaf spot caused by Lasiodiplodia hormozganensis in China
}

\author{
Shaogang Zhang ${ }^{1,2} \cdot$ Meijiao $\mathrm{Hu}^{3} \cdot$ Chao Zhao ${ }^{1,2} \cdot \mathrm{Yi} \mathrm{Wang}^{1,2} \cdot{\mathrm{Min} \mathrm{Li}^{3}}^{3} \cdot$ Zhaoyin Gao $^{3} \cdot$ Chunxia $\mathrm{Li}^{3} \cdot \mathrm{Jing} \mathrm{Yu}^{4}$ \\ Received: 4 April 2020 /Revised: 10 September 2020 / Accepted: 18 September 2020 / Published online: 1 October 2020 \\ (C) Società Italiana di Patologia Vegetale (S.I.Pa.V.) 2020
}

Keywords Scaevola taccada $\cdot$ Leaf spot $\cdot$ Lasiodiplodia hormozganensis

A leaf spot of Scaevola taccada was observed on the Xisha Islands of China in May 2018. 5-10\% of leaves were infected. The typical symptoms were brown lesions with yellow edges on the leaf tips or margins. Twenty diseased leaf sections $(4 \mathrm{~mm} \times$ $4 \mathrm{~mm}$ ) were surface-sterilized, plated on potato dextrose agar (PDA) and incubated at 28 in the dark for 48 hours. Morphologically similar colonies were isolated from all samples. The isolate JQD-3 was randomly selected for identification and pathogenicity test. The colony was circular, white with radiating aerial mycelia, and then became dark-green. After 20 days, black grouped globular pycnidia were developed. Conidia were produced in pycnidia, ellipsoidal to cylindrical, initially hyaline, unicellular to dark brown, a central septum and striated at maturity, 19.5-23.1 $\mu \mathrm{m} \times 11.6-13.3 \mu \mathrm{m}(\mathrm{n}=100)$. The internal transcribed spacer of rDNA region (ITS), $\beta$-tubulin (TUB) and translation elongation factor $1-\alpha(\mathrm{EF} 1-\alpha)$ genes were sequenced using the primers of ITS1/ITS4 (White et al. 1990), Bt2a/Bt2b (Glass and Donaldson 1995) and EF1-728F/EF1-986R (Carbone and Kohn 1999), respectively. The obtained sequences were deposited in GenBank (MN832616, MN848235 and MN848236). Nucleotide BLAST analysis showed common 99\% similarity with Lasiodiplodia hormozganensis for ITS (KP822969), TUB

Shaogang Zhang and Meijiao Hu contributed equally to this work.

Chao Zhao

244062891@qq.com

1 School of Life and Pharmaceutical Sciences, Hainan University, Haikou 570228, China

2 Key Laboratory of Tropical Biological Resources of Ministry of Education, Hainan University, 570228 Haikou, China

3 Environment and Plant Protection Institute, Chinese Academy of Tropical Agricultural Science, 571101 Haikou, China

4 College of Plant Protection, Hainan University, Haikou 570228, China
(KP823005) and EF1- $\alpha$ (KP822987), respectively. Pathogenicity tests were performed using 30 young detached leaves of $S$. taccada for three times. Five-mm diameter mycelial plugs were deposited on wounded leaves. The control was inoculated with sterile PDA medium, and maintained at $25^{\circ} \mathrm{C}$ in a growth chamber. One day after inoculation, the inoculated leaves showed unambiguous brown spots, while the leaves of control remained symptomless. The same fungus was only re-isolated from symptomatic leaves. To our knowledge, this is the first report of leaf spot on S. taccada caused by L. hormozganensis.

Acknowledgements This research was financially supported by the Ministry of Agriculture and Rural Affairs, P. R. China (No. NFZX2018).

\section{Compliance with ethical standards}

Conflict of interest The authors declare that they have no conflict of interest.

Research involving human participants and/or animals The authors declare that no human participants and animals were involved in this study.

Informed consent This manuscript is new and not being considered elsewhere. All authors have approved the submission of this manuscript.

\section{References}

Carbone I, Kohn LM (1999) A method for designing primer sets for speciation studies in filamentous ascomycetes. Mycologia 91(3): 553-556

Glass NL, Donaldson GC (1995) Development of primer sets designed for use with the PCR to amplify conserved genes from filamentous ascomycetes. Appl Environ Microbiol 61(4):1323-1330

White TJ, Bruns T, Lee S, Taylor J (1990) Amplification and direct sequencing of fungal ribosomal RNA genes for phylogenies. In: Innis MA, Gelfand DH, Sninsky JJ, White TJ (eds) PCR protocols: A guide to methods and applications. Academic, San Diego, pp 315-322 